\title{
HUBUNGAN ANTARA BERAT BADAN BAYI BARU LAHIR PADA PERSALINAN FISIOLOGIS DENGAN KEJADIAN RUPTUR PERINEUM Studi di BPS Ny.Yuliana,Amd.Keb Banjaranyar Kecamatan Lamongan Kabupaten Lamongan 2015
}

\author{
Fitriana Ikhtiarinawati Fajrin* \\ Elis Fitriani** \\ *Dosen Program Studi D III Kebidanan Universitas Islam Lamongan \\ **Mahasiswa Program Studi D III Kebidanan Universitas Islam Lamongan
}

\begin{abstract}
ABSTRAK
Berat bayi lahir merupakan faktor resiko yang meningkatkan kejadian perlukaan perineum. Semakin besar bayi yang dilahirkan beresiko terjadinya rupture perineum. Di BPS Ny.Yuliana masih tinggi angka kejadian rupture perineum $60,3 \%$ ibu bersalin fisiologis. Peneliti bertujuan untuk mengetahui hubungan berat badan bayi baru lahir dengan kejadian rupture perineum. Persalinan fisiologis masih beresiko terhadap kejadian rupture perineum.

Desain penelitian menggunakan Analitik observasional pendekatan cross sectional. Populasi penelitian ibu bersalin fisiologis sebanyak 25 responden. Jumlah sampel sebanyak 24 responden, diambil dengan cara Simple Random Sampling. Instrumen penelitiannya adalah patograf. Variabel independent berat badan bayi baru lahir dan variabel dependent kejadian rupture perineum. Analisa Data korelasional, Data yang diperoleh diolah menggunakan SPSS dengan uji Koefisien kontingensi tingkat kemaknaan $p<0,05$.

Hasil penelitian menunjukkan hampir seluruhnya responden. Kejadian rupture perineum terbesar pada berat badan normal 2500-3500gram 90,5\%, yang mengalami rupture perineum terkecil pada berat badan kecil $<2400$ gram $0 \%$. Kemudian dilakukan uji statistik koefsien kontingensi didapatkan $\mathrm{Ch}=0,487 \mathrm{Ct}=$ 0.024 lalu dibandingkan dengan nilai $p<0,05$ hasilnya Ho ditolak.

Kesimpulan penelitian yakni ada hubungan antara berat badan bayi baru lahir pada persalinan fisiologis dengan kejadian rupture perineum. Kejadian ruptur perineum tidak hanya terjadi disebabkan berat badan bayi, ada beberapa faktor yang mengakibatkan ruptur yaitu perineum kaku dan elastisitas perineum. Maka diharapkan ada penelitian berikutnya yang meneliti tentang berat badan yang mengakibatkan ruptur.
\end{abstract}

Kata Kunci : Berat Badan Bayi Baru lahir, Ruptur Perineum Spontan 


\section{PENDAHULUAN}

Mortalitas dan morbiditas pada wanita bersalin adalah masalah besar di Negara berkembang, termasuk di Indonesia. Kematian saat melahirkan biasanya menjadi faktor utama mortalitas wanita mudah pada masa puncak produktivitasnya. Berat bayi lahir merupakan salah satu faktor resiko yang meningkatkan kejadian perlukaan perineum selama kelahiran. Semakin besar bayi yang dilahirkan meningkatkan resiko terjadinya rupture perineum, pada normalnya berat badan bayi sekitar 2.500-3.800 gram (Rini Sekartini, 2007:54).

Indonesia membuat rencana strategi nasional Making Pregnancy Safer (MPS) untuk tahun 2001-2010, dalam konteks rencana pembangunan kesehatan menuju Indonesia Sehat 2014 adalah dengan visi "Kehamilan dan Persalinan di Indonesia Berlangsung Aman, serta yang dilahirkan Hidup dan Sehat," dengan misinya adalah menurunkan angka kesakitan dan kematian maternal dan neonatal melalui pemantapan sistem kesehatan. Salah satu sasarannya ditetapkan untuk tahun 2010 adalah menurunkan angka kematian maternal menjadi 125 per 100.00 kelahiran hidup (Saiffudin, 2006:4)

Angka Kematian Ibu (AKI) di Indonesia yaitu 390 per 100.000 kelahiran hidup (SDKI,1994) tertinggi di ASEAN (Association of South East Asia Nation). Berdasarkan SKRT tahun 1995 Angka Kematian Ibu (AKI) adalah 373/100.000 kelahiran hidup, sedangkan pada tahun 2003 AKI turun menjadi 307/100.00 kelahiran hidup (SDKI,2003).
Sementara itu, umur harapan hidup rata-rata meningkat dari 63,20 tahun pada tahun 1995 menjadi 66,2 tahun pada tahun 2003 (SDKI,2003). ASEAN (Assosiation of South East Asia Nation) menempatkan upaya penurunan Angka Kematian Ibu AKI) sebagai program prioritas. Penyebab langsung kematian ibu di Indonesia sepeti halnya di Negara lain adalah perdarahan, infeksi, dan eklamsia. Salah satu kematian ibu di Indonesia disebabkan oleh perdarahan postpartum(Hanifa

Winkjosastro,2005:23). Perdarahan postpartum menjadi penyebab utama $40 \%$ kematian ibu di Indonesia. Sedangkan robekan jalan lahir merupakan peyebab kedua tersering dari pendarahan postpartum. Robekan dapat terjadi bersamaan dengan Antonia uteri. Perdarahan postpartum dengan uterus yang berkontraksi baik biasanya disebabkan oleh sobekan servik atau vagina (Bobak,2002:713). Robekan jalan lahir (Ruptur) adalah luka pada perineum yang diakibatkan oleh rusaknya jaringan secara alamiah karena proses desakan kepala janin atau bahu pada saat proses persalinan (Hamilton, 2002:302)

Berdasarkan hasil data prasurvey, angka kejadian rupture perineum spontan yang dialami ibu bersalin fisiologis di BPS Ny.Yuliana,Amd.Keb dari bulan Januari sampai Maret tahun 2015 masih sangat tinggi yaitu sebanyak 58 ibu bersalin fisiologis, 35 ibu bersalin fisiologis yang mengalami rupture perineum dan yang tidak mengalami rupture perineum berjumlah 23 orang. Dari penjabaran di atas menunjukkan 
masih tingginya kejadian rupture perineum pada ibu bersalin fisiologis.

Rupture Perineum dapat terjadi karena adanya rupture spontan maupun episiotomy. Rupture perineum secara spontan dapat disebabkan oleh tiga faktor, yaitu dari faktor ibu, faktor janin dan faktor penolong persalinan (Rustam Mochtar,2003:111).

Faktor ibu antara lain partus presipitarus, primigravida, persalinan operative pervaginam, pintu panggul yang sempit. Faktor janin antara lain kepala janin besar dan janin besar, presentasi defleksi, letak sungsang dan after coming head, makrosomia, diastosia bahu, berat badan bayi. Menurut Hanifa Winkjosastro salah satu faktor yang menyebabkan robekan perineum yaitu perineum kaku dan episiotomy.

Penelitian mengiginkan agar tercipta persalinan yang aman, tepat dan terencana, agar bisa meminimalkan kejadian rupture perineum di harapkan penolong dapat melakukan pimpinan meneran pada ibu apabila TBJ lebih besar jadi penolong bisa melakukan episiotomy pada persalinan dengan indikasi,agar rupturnya teratur dan mempercepat kesembuhan. ( Sarwono 2008:187 ).

Berdasarkan data tersebut penulis tertarik untuk meneliti hubungan antara berat badan lahir pada persalinan fisiologis dengan kejadian rupture perineum di BPS Yuliana,Amd.Keb tahun 2015.

\section{PEMBAHASAN}

Hasil pengumpulan data melalui pengamatan tentang hubungan antara berat badan bayi baru lahir pada persalinan fisiologis dengan kejadian rupture perineum yang di lakukan pada responden di BPS Ny. Yuliana Amd, Keb. Bulan juni sampai juli tahun 2015 Banjaranyar, Kecamatan Lamongan, Kabupaten Lamongan.

Hasil penelitian ini meliputi hubungan antara berat badan bayi baru lahir pada persalinan fisiologis dengan kejadian rupture perineum dengan data umum dan khusus. Data umum (umur dan paritas), data khusus (berat badan bayi baru lahir dan rupture perineum) di BPS Ny. Yuliana Amd,Keb., Banjaranyar Kecamatan Lamongan Kabupaten Lamongan.

\section{Hasil Penelitian}

Data Umum

1. Usia

Tabel 1 Distribusi responden berdasarkan usia di BPS Ny.Yuliana, Amd.Keb Di Banjaranyar Kecamatan Lamongan Kabupaten Lamongan tahun 2015.

\begin{tabular}{|c|c|c|c|}
\hline \multirow[t]{2}{*}{ No } & \multirow[t]{2}{*}{ Usia } & & \\
\hline & & Jumlah & $\%$ \\
\hline 1. & $<20$ tahun & 0 & 0 \\
\hline 2. & 21-33 tahun & 16 & 66,7 \\
\hline 3. & $<34$ tahun & 8 & 33,3 \\
\hline & Jumlah & 24 & 100 \\
\hline
\end{tabular}

didapatkan data sebagian besar responden berusia 21 - 33 tahun 16 responden $(66,7 \%)$.

2. Paritas

Tabel 2 Distribusi responden berdasarkan paritas di BPS Ny.Yuliana, Amd.Keb Di Banjaranyar Kecamatan Lamongan Kabupaten Lamongan tahun 2015. 


\begin{tabular}{|l|c|l|}
\hline Paritas & Jumlah & $\%$ \\
\hline Primigravida & 13 & 54,2 \\
Multigravida & 10 & 41,7 \\
Grandemulti & 1 & 4,2 \\
\hline Jumlah & 24 & 100 \\
\hline
\end{tabular}

Dari tabel di atas didapatkan data sebagian besar responden ibu bersalin yang melahirkan primigravida yaitu 13 responden $(54,2 \%)$.

Data Khusus

Data yang terkumpul sejumlah 24 responden, dengan karakteristik responden meliputi bayi baru lahir dengan persalinan fisiologis.

Untuk pemaparan dapat di lihat dalam table di bawah ini :

Tabel 3 Distribusi responden berat badan bayi baru lahir pada persalinan fisiologis di BPS Ny.Yuliana,Amd.Keb, Di Banjaranyar Kecamatan Kabupaten Lamongan tahun 2015.

\begin{tabular}{|l|lr|c|c|}
\hline No & $\begin{array}{l}\text { Berat } \\
\text { Bayi }\end{array}$ & $\begin{array}{r}\text { Badan } \\
\text { Lahir }\end{array}$ & Jumlah & $\%$ \\
\hline 1. & Besar $\geq 3500$ & 2 & 8,3 \\
2. & Normal 2500- & 21 & 87,5 \\
3. & 3500 & 1 & 4,2 \\
& Kecil $\leq 2400$ & & \\
\hline & \multicolumn{2}{|c|}{ Jumlah } & 24 & 100 \\
\hline
\end{tabular}

Dari tabel di atas didapatkan data hamper seluruhnya responden berat badan bayi baru lahir dengan berat badan normal 2500 - 3500 gram yaitu 21 responden $(87,5 \%)$.

Tabel 4 Distribusi responden berdasarkan kejadian rupture perineum pada persalinan fisiologis di
BPS Ny.Yuliana, Amd.Keb. Di Banjaranyar Kecamatan Lamongan Kabupaten Laongan tahun 2015.

\begin{tabular}{|l|l|c|l|}
\hline No & $\begin{array}{c}\text { Ruptur } \\
\text { Perineum }\end{array}$ & Jumlah & $\%$ \\
\hline 1. & & 21 & 87,5 \\
2. & Ruptur & 3 & 12.5 \\
& Intak & & \\
\hline & Jumlah & 24 & 100 \\
\hline
\end{tabular}

Dari Tabel di atas didapatkan data hamper seluruhnya responden Ibu bersalin yang mengalami rupture perineum yaitu 21 responden $(87,5 \%)$.

Untuk memperoleh gambaran ada tidaknya hubungan antara variable berat badan bayi baru lahir dengan kejadian rupture perineum maka dibuat tabulasi silang (cross table) terhadap variable tersebut dengan pembuktian hipotesa dengan menggunakan uji koefisiesi kongtinensi.

Tabel 5 Tabel silang hubungan berat badan bayi baru lahir pada persalinan fisiologis dengan kejadian rupture perineum. Di Banjaranyar Kecamatan Lamongan Kabupaten Lamongan tahun 2015.

\begin{tabular}{|c|c|c|c|c|c|c|}
\hline Berat Badan & \multicolumn{4}{|c|}{ Ruptur Perineum } & \multicolumn{2}{c|}{ Total } \\
\cline { 2 - 7 } $\begin{array}{c}\text { Bayi Baru } \\
\text { Lahir }\end{array}$ & $\begin{array}{c}\text { Rupt } \\
\text { ur }\end{array}$ & $\%$ & Intak & $\%$ & \multicolumn{2}{c|}{$\begin{array}{c}\text { Jumlah } \\
\%\end{array}$} \\
\hline Besar $\geq 3500$ & 2 & 9,5 & 0 & 0 & 2 & 100 \\
Normal & 19 & 90,5 & 2 & 9,5 & 21 & 100 \\
$2500-3500$ & 0 & 0 & 1 & 4,2 & 1 & 100 \\
Kecil $\leq 2400$ & & & & & & \\
& & & & & & \\
\hline Jumlah & 21 & 87,5 & 3 & 12, & 24 & 100 \\
\hline
\end{tabular}




$$
\mathrm{C}=0,024 \quad \mathrm{P}>0,05
$$

Berdasarkan tabel di atas didapatkan data terbesar responden tentang karakteristik berat badan bayi lahir data terbesar responden dengan berat badan bayi normal 25003500 gram yaitu 19 responden $(90,5 \%)$ sedangakan data terkecil responden dengan berat badan bayi lahir kecil $\leq 2400$ gram yaitu 0 respoden $(0 \%)$. Dan di dapatkan data tentang karakteristik rupture perineum data terbesar responden yang mengalami rupture perineum yaitu pada berat badan bayi lahir normal 25003500 gram yaitu 19 responden $(90,5 \%)$, sedangkan data terbanyak yang tidak mengalami rupture yaitu pada berat badan normal 2500-3500gram yaitu 2 responden $(9,5 \%)$.

\section{Analisis Data}

Dari data yang sudah di tabulasi kemudian dianalisis mengguakan Uji koefisien kontingensi didapatkan nilai $\mathrm{C}=0,024$ dimana $\mathrm{p}>0,05$ hal ini menunjukkan bahwa Ho ditolak artinya ada hubungan antara berat badan bayi baru lahir pada persalinan fisiologis dengan kejadian rupture perineum $\quad \mathrm{di}$ BPS Ny.Yuliana,Amd.Keb. Di Banjaranyar kecamatan Lamongan Kabupaten Lamongan Kabupaten Lamongan Tahun 2015.

\section{PEMBAHASAN}

Analisis data berat badan bayi baru lahir pada persalinan fisiologis dengan kejadian rupture perineum yang di peroleh dari hasil penelitian yang di laksanakan di BPS Ny. Yuliana,Amd.Keb Banjaranyar
Kecamatan Lamongan Kabupaten Lamongan.

\section{Berat Badan Bayi Baru Lahir}

Hasil penelitian di lakukan terhadap 24 responden, menunjukkan bahwa dari ibu bersalin 24 ibu bersalin hampir seluruh responden yaitu 21 responden $(87,5 \%)$ dengan berat badan bayi lahir dengan berat badan normal 2500-3500gram. Sedangkan responden berat badan bayi lahir dengan berat badan besar $\geq 3500$ yaitu 2 responden $(8,3 \%)$. Dan responden yang berat badan bayi lahir dengan berat badan kecil $\leq 2400$ gram yaitu 1 responden $(4,2 \%)$. Hal ini menunjukkan bahwa hampir seluruh bayi lahir dengan berat badan bayi baru lahir normal 25003500gram.

Berat badan lahir merupakan berat badan bayi yang di timbang 24 jam pertama setelah kelahiran (Rini sekartini , 2007:35)

Menurut penelitian Albers LL kandung kemih menyataka bahwa berat bayi lahir merupakan salah satu faktor risiko yang meningkatkan kejadian perlukaan perineum selama kelahiran. Semakin besar bayi yang dilahirkan meningkatkan resiko terjadinya rupture perineum, pada bayi besar $\geq 3500$ gram, normalnya berat badan bayi sekitar 2.500-3.500 gram, dan berat bayi kecil $\leq 2400$ gram. (Rini Sekartini, 2007:54).

Bayi dapat lahir dengan berat badan normal dikarenakan ibu memenuhi nutrisi seimbang selama hamil serta keteraturan ibu untuk periksakan kehamilan secara rutin di bidan. Oleh karena itu pemeriksaan kehamilan harus rutin untuk memantau penambahan berat badan ibu hamil 
sehingga bayi dapat lahir dengan berat badan normal. Semakin besar berat badan bayi mengakibatkan kejadian rupture perineum.

\section{Ruptur Perineum}

Hasil penelitian menunujukkan bahwa dari 24 ibu bersalin terbesar responden yaitu 21 responden $(87,5 \%)$ yang terjadi rupture, dan responden yang tidak terjadi rupture yaitu 3 responden $(12,5 \%)$.

Hasil penelitian menunjukan masih banyak kejadian rupture perineum pada ibu bersalin fisiologis. Hal ini dapat di sebabkan oleh perineum kaku, paritas (primigravida), presentasi bukan belakang kepala, cara meneran yang salah, bayi besar serta penggunaan perasat manual yang kurang tepat.

Robekan jalan lahir (Ruptur) adalah luka pada perineum yang diakibatkan oleh rusaknya jaringan secara alamiah karena proses desakan kepala janin atau bahu pada saat proses persalinan. (Hamilton,2002:302).

Rupture perineum secara spontan dapat disebabkan oleh tiga faktor, yaitu dari faktor ibu, faktor janin dan faktor penolong persalinan (Rustam Mochtar,2003:111).

Intak adalah tidak terdapat rusakan jaringan yang terputus pada saat persalinan fisiologis. (Rustam Mochtar,2003:118)

Faktor ibu antara lain partus presipitarus, primigravida, persalinan operative pervaginam, pintu panggul yang sempit. Faktor janin antara lain kepala janin besar, janin besar, berat badan bayi, presentasi defleksi, letak sungsang dan after coming head, makrosomia, diastosia bahu, abnormalitas congenital. Menurut
Hanifa Winkjosastro (2005:665) salah satu faktor yang menyebabkan robekan perineum yaitu perineum kaku.

Agar tercipta persalinan yang yang aman, tepat dan terencana maka seharusnya penolong meminimalkan kejadian rupture perineum dan penolong dapat melakukan episiotomy agar rupturnya teratur dan memprcepat kesembuhan.

\section{Hubungan Antara berat badan bayi baru lahir pada peralinan fisiologis dengan kejadian rupture perineum}

Hasil penelitian terbesar responden berat badan bayi normal 2500-3500gram yaitu 19 responden $(90,5 \%)$ sedangkan terkecil responden dengan berat badan bayi lahir kecil $\leq 2400$ gram yaitu 0 respoden $(0 \%)$. Dan di dapatkan data tentang karakteristik rupture perineum data terbesar responden yang mengalami rupture perineum yaitu responden yaitu 21 responden $(87,5 \%)$ yang terjadi ruptur, dan responden yang tidak terjadi rupture yaitu 3 responden $(12,5 \%)$.

Hasil dari tabulasi silang berat badan bayi normal 2500-3500gram yang mengalami rupture adalah 19 responden $(90,5 \%)$ sedangkan berat badan bayi besar >3500gram yang mengalami rupture adalah 2 responden $(9,5 \%)$, dan berat badan bayi kecil $<2400$ gram adalah 0 responden $(0 \%)$. Dari data tabulasi silang yang tidak mengalami rupture yaitu pada berat badan bayi besar $>3500$ gram adalah 0 responden $(0 \%)$ sedangkan pada berat badan bayi normal 2500-3500gram adalah 2 responden $(9,5 \%)$ yang tidak mengalami rupture, dan berat badan bayi kecil <2400gram adalah 1 
responden $(4,2 \%)$ yag tidak mengalami rupture.

Dari hasil analisa statistic uji koefisien kontingensi menunjukkan bahwa terdapat hubungan yang signifikan antara berat bada bayi baru lahir dengan kejadian rupture perineum dengan nilai $\mathrm{C}=0,024 \mathrm{di}$ mana $\mathrm{p}>0,05$ maka $\mathrm{HO}$ di tolak artinya ada hubungan antara berat badan bayi baru lahir pada persalinan fisiologis dengan kejadian rupture perineum.

\section{KESIMPULAN}

Setelah mengetahui dan mempelajari hasil penelitian melalui analisa data dan pembahasan, pada bab ini akan di uraikan tentang simpulan dan saran dari hasil penelitian yang berjudul " Hubungan Antara Berat Badan Bayi Baru Lahir Pada Persalinan Fisiologis Dengan Kejadian Ruptur Perineum".

Berdasarkan hasil penelitian dan pembahasan melalui hubungan antara berat badan bayi baru lahir pada persalinan fisiologis dengan kejadian rupture perineum di BPS $\mathrm{Ny}$. Yuliana,Amd.Keb Banjaranyar Kecamatan Lamongan Kabupaten Lamongan, dapat di rumuskan sebagai berikut :

a. Hampir seluruhnya berat badan bayi lahir pada persalinan fisiologis dengan berat badan normal 25003500gram. Di BPS Ny. Yuliana,Amd.Keb Banjaranyar, Kecamatan Lamongan, Kabupaten Lamongan

b. Hampir seluruhnya ibu bersalin fisiologis mengalami rupture perineum. Di BPS Ny.Yuliana,
Amd.Keb Banjaranyar, Kecamatan Lamongan, Kabupaten Lamongan.

c. Terdapat hubungan antara berat badan bayi baru lahir pada persalinan fisiologis dengan kejadian rupture perineum nilai $\mathrm{C}=$ 0,024 di mana $p>0,05$ di BPS Ny. Yuliana, Amd.Keb Banjaranyar, Kecamatan Lamongan, Kabupaten Lamongan.

\section{Saran}

a. Bagi Pihak Institusi Pendidikan. Hasil Karya Tulis Ilmiah ini dapat menambah kajian ilmu dalam bidang kesehatan dan sebagai bahan wacana di perpustakaan untuk seluruh mahasiswi Universitas Islam Lamongan.

b. Bagi Praktisi. Dengan adanya hasil Karya Tulis Ilmiah ini, peneliti dapat menambah banyak wawasan keilmuannya. Sebagai sumber informasi dalam pelayanan kesehatan dan meningkatkan kualitas pelayanan kesehatan dalam asuhan manajemen asuhan persalinan fisiologis dengan penanganan kejadian rupture perineum.

c. Bagi Sarana. Untuk masyarakat khususnya keluarga untuk selalu memberikan dukungan kepada ibu untuk keteraturan periksakan kehamilan untuk memantau penambahan berat badan ibu hamil, semakin besar berat badan bayi akan mengakibatkan kejadian rupture perineum.

\section{DAFTAR PUSTAKA}

Alimul,H,A. 2007. Pengantar kebutuhan dasar manusia 
aplikasi dan prosedur keperawatan. Jakarta : salemba medika.

Arikunto, 2006. Prosedur Penelitian Suatu Pendekatan Praktik. Edisi 4. Jakarta

PT. Rineka Cipta.

Bobak, 2008. Buku Ajar Keperawatan Maternitas; Edisi 4, Jakarta EGC.

Cunningham, Gary, 2006. Ilmu kebidanan : Edisi 2, Jakarta : EGC.

DEPKES RI, 2008. Buku Acuan Pelatihan Asuhan Persalinan Dasar. Jakarta: DRAFT.

Dorland, 2009. Ilmu kebidanan : Edisi 4, Jakarta : EGC.

Hamilton, persis M. 2002, dasar dasar keperawatan maternitas Jakarta : EGC

Hanifa Wiknjosastro, 2006. Ilmu Kebidanan. Edisi :2, Jakarta : EGC

Hidayat A,aziz alimul, 2007. Riset keperawatan dan teknik penulisan ilmiyah, Jakarta :EGC.

Ida Bagus Gde Manuaba, 2007. Ilmu Kebidanan, Penyakit Kandungan Dan Maimunah, 2005. Kamus Istilah Kebidanan. Jakarta : EGC.

Jhonson,2007. Ilmu kebidanan : Edisi 3, Jakarta :EGC.

Mansjor, 2009. Kapita selekta kedokteran, Edisi 3 cetakan 1, Jakarta : EGC.

Mohtar Rustam, 2009. Obstetri Fisiologi dan Obststri
Patologi, Jilid 1, Edisi 2. Jakarta : EGC.

Nursalam, 2003. Konsep dan Penerapan Metodologi Penelitian dan Ilmu Keperawatan. Salemba Medika: Jakarta.

Notoatmodjo, 2008. Ilmu Kesehatan Masyarakat, Edisi 2. Jakarta : RINEKA CIPTA.

Oxom, 2007. Ilmu Kebidanan ; Edisi 3, Jakarta EGC.

Rayburn, 2009, Buku Ajar Keperawatan Maternitas. Jakarta: EGC.

Rini, Sekartini, 2007. Buku Panduan Praktis Pelayanan Kesehatan Maternal dan Neonata. Jakarta : YBP-SP.

Saifuddin, 2008. Buku Panduan Praktis Pelayanan Kesehatan Maternal dan Neonata. Jakarta : YBP-SP.

Sarwono Prawiroharjo, 2009. Ilmu Kebidanan ; Edisi 6, Jakarta EGC.

Sugiyono, 2006. Metode Penelitian Administrasi. Jakarta

ALFABETA.

Suparmoko, 1997. Metode penelitian ilmu keperawatan, Jakarta : salemba medika.

Winkjosastro. Hanafi, 2007. Ilmu kebidanan, Jakarta : EG 